\title{
FORMULATION AND EVALUATION OF MICROEMULSION GEL FOR TRANSDERMAL DELIVERY OF TRAMADOL
}

\author{
MURUGANANTHAM V*, PRABAKARAN M, PASUPATHI C, PEELY LR, POOJA B
}

Department of Pharmaceutics, Vinayaka Mission's College of Pharmacy, Vinayaka Mission's Research Foundation, Salem, Tamil Nadu, India. Email: svmanand@gmail.com

Received: 08 February 2019, Revised and Accepted: 09 April 2019

\section{ABSTRACT}

Objective: The present work was carried out to design microemulsion gel system for transdermal delivery of the drug to minimize the side effects and to reduce the frequency of administration and for prolonging the duration of action.

Methods: Tramadol, an opioid analgesic drug, was mixed with various selected polymers such as sodium alginate (SA), acacia, hydroxypropyl methylcellulose (HPMC), and Eudragit in geometric mixing ratios. The drug, polymer, and other excipients were mixed thoroughly by trituration method and different formulations (F1-F8) were prepared the same quantity of all the ingredients excepting the polymers.

Results: The different formulations prepared, studied, and showed that the formulation using SA as polymeric carrier had a better effect on the evaluated parameters. The drug-SA formulation exhibited better drug-polymer compatibility, optimal viscosity (2750 cps), zeta potential ( $-26.1 \mathrm{Mv}$ ), and particle size distribution ( $262.8 \mathrm{~d} . \mathrm{nm})$ values. The in vitro release studies also indicated that the drug-SA formulation was of desirable release pattern, thus indicating that SA to be a better choice in formulating a transdermal delivery gel system.

Conclusion: Evaluated microemulsion gel formulation F2 of tramadol with polymeric carriers SA was much stable than other carriers used. Thus, it could be concluded that the gel formulation with SA can be taken as an ideal formulation.

Keywords: Tramadol, Microemulsion gel, Transdermal drug delivery system.

(C) 2019 The Authors. Published by Innovare Academic Sciences Pvt Ltd. This is an open access article under the CC BY license (http://creativecommons. org/licenses/by/4. 0/) DOI: http://dx.doi.org/10.22159/ajpcr.2019.v12i5.32479

\section{INTRODUCTION}

Microemulsion is defined as an oil-in-water or water-in-oil emulsion producing a transparent product [1]. Techniques for enhancement of transdermal permeation of drugs are the use of nanoemulsion and microemulsion vehicles [2]. Microemulsions have received great attention for various applications including dermal and transdermal drug delivery due to ease of preparation, thermodynamic stability, permeation enhancement activity of their components, and a high solubilizing capacity for various drugs over conventional topical formulation vehicles [3]. Microemulsions are known to enhance the bioavailability of drugs through topical and systemic routes. Microemulsion prepared and it's evaluated and this microemulsion incorporated in suitable gelling agent. Microemulsions possess a certain degree of elegance and are easily washed off whenever desired. They also have a high ability to penetrate the skin [4].

The ingredients of microemulsion could facilitate the permeation rate of the drug by reducing the diffusion barrier of the stratum corneum. However, due to low viscosity of the microemulsions, their minimal retention in the affected part imposes a resistance in its widespread use in pharmaceutical industry. It is important to prevent the drug loss due to draining out from the onycholytic cavity or reaching the systemic circulation. To circumvent these problems, the colloidal drug delivery carrier should be loaded in a gel base [5,6] In recent years, microemulsions continued to be used as solubilization capacity enhancers and dissolution rate improvers for poorly soluble drugs. The works in this area focus on two aspects: First, the effect of different microemulsion structures on drug solubilization capacity and dissolution efficiency, and second, on the physicochemical characterization of drug-loaded microemulsions compared to drug-free systems [7].
Microemulsion-based gels possess the previously mentioned advantages of both emulsions and gels such as better stability, better loading capacity, incorporation of hydrophobic drugs, and avoidance of the first pass effect and also have good patient acceptability. Advantages associated with low-surfactant microemulsion gels were formulated and characterized to enhance topical delivery of poorly soluble drugs. It was found that the choice of viscosity imparting agent played an important role in governing drug release from microemulsion gel. Microemulsion-based gels now have been used for the treatment of various kinds of skin disorder [8]. Topical drug delivery can be defined as the application of a drug containing formulation to the skin to directly treat the cutaneous disorders. Topical drug delivery system has several advantages such as ability to deliver drug more selectively to a specific site, avoidance of gastrointestinal incompatibility, and metabolic degradation associated with oral administration. Moreover, topical deliveries provide an increased bioavailability by avoiding the first pass metabolism by liver and a consistent delivery for extended period. In topical drug delivery system, drug diffuses out of the delivery system, reaches to the site of action, and gets absorbed by the skin [9].

The aim of this study was to develop suitable microemulsion gel system (without addition of gelling agent) after screening of oils, surfactants, and cosurfactants for transdermal delivery of tramadol to enhance its dissolution and to improve its skin permeability with enhanced safety.

\section{MATERIALS AND METHODS}

Materials

Tramadol was received as a gift sample from Zydus Cadila Healthcare Ltd., Ahmedabad, Gujarat. Sodium alginate (SA), Acacia, hydroxypropyl methylcellulose (HPMC), Eudragit, Tween-80, sodium lauryl sulfate, 
castor oil, and methylparaben were used as gelling agents and additives. All reagents and solvents used were of analytical grade.

\section{Methods}

Preparation of microemulsion gel of tramadol

Tramadol was mixed with different polymers such as SA, Acacia, HPMC, and Eudragit by geometric mixing. Drug, polymer, and other excipients were mixed thoroughly by trituration method and eight different formulations were prepared in which the amount of all the ingredients

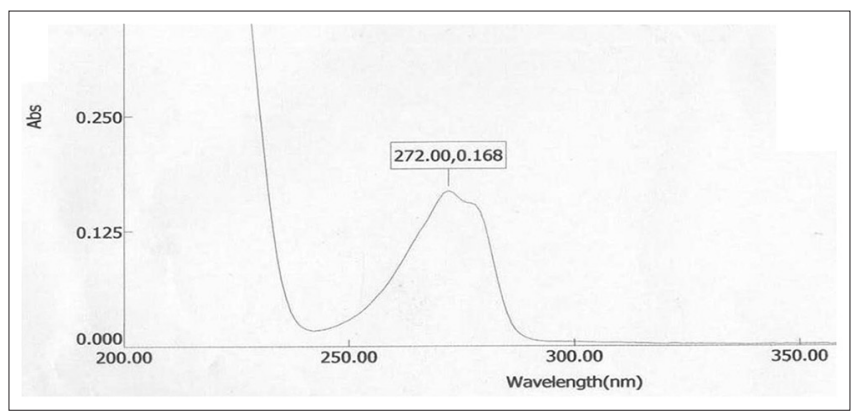

Fig. 1: Ultraviolet spectrum of pure tramadol

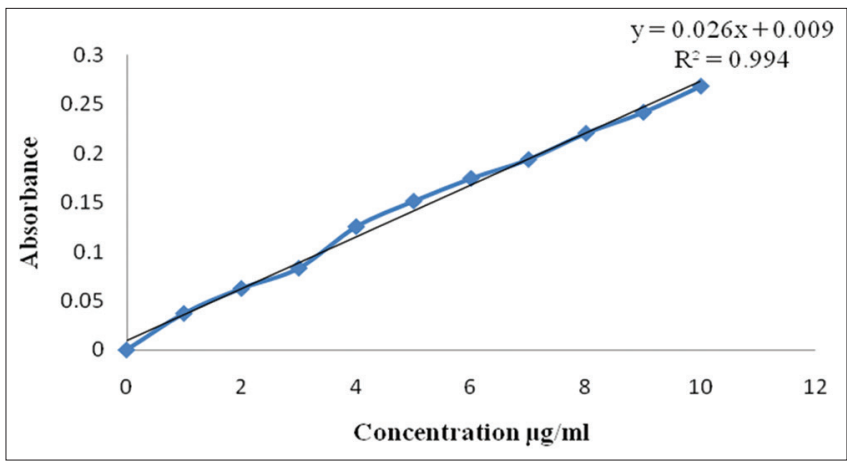

Fig. 2: Standard calibration curve of tramadol (except polymers) was kept constant including drug. The detail of composition of each formulation is given in Table 1.

\section{Evaluation of tramadol microemulsion gel}

Evaluated parameters for the gel formulations were appearance, $\mathrm{pH}$, viscosity, spreadability, extrudability, zeta potential, in-vitro drug diffusion study.

pH [10]

The $\mathrm{pH}$ value conventionally represents the acidity or alkalinity of solution in the pharmacopoeia, standard and limit of $\mathrm{pH}$ have been provided for those pharmacopoeial substances in which $\mathrm{pH}$ as a measure of the hydrogen ion activity is important from the standpoint of stability.

The $\mathrm{pH}$ of gel was checked using a digital $\mathrm{pH}$ meter at constant temperature. Before this, the $\mathrm{pH}$ meter was calibrated using phosphate buffer solution of $\mathrm{pH} 3.99,7.0$, and 9.2, and then, the electrode was washed with dematerialized water. The electrode was then directly dipped into gel formulation and constant reading was noted. The results are mentioned in Table 2 .

\section{Viscosity [10,11]}

Viscosity of the formulated microemulsion gel was determined using Brookfield viscometer at $25^{\circ} \mathrm{C}$. The results are mentioned in Table 3 .

\section{Spreadability [10]}

Spreadability of the formulations was determined by texture analyzer apparatus suitably modified for the study. The spreadability was calculated using the formula.

$\mathrm{S}=\mathrm{ML} / \mathrm{T}$

Where,

S=Spreadability

$\mathrm{M}=$ Weight tied to upper glass slide

$\mathrm{L}=$ Length of glass slide

$\mathrm{T}=$ Time taken in seconds.

The results are mentioned in Table 3 and Fig. 13

Table 1: Composition of tramadol microemulsion gel with different polymer concentrations

\begin{tabular}{llllllllll}
\hline S. No. & Ingredients & F1 & F2 & F3 & F4 & F5 & F6 & F7 & F8 \\
\hline 1 & Tramadol (mg) & 1000 & 1000 & 1000 & 1000 & 1000 & 1000 & 1000 & 1000 \\
2 & SA (mg) & 1000 & 2000 & - & - & - & - & - & - \\
3 & Acacia (mg) & - & - & 1000 & 2000 & - & - & - \\
4 & HPMC (mg) & - & - & - & - & 1000 & 2000 & - & - \\
5 & Eudragit (mg) & - & - & - & - & - & - & 1000 & 2000 \\
6 & Tween 80 (mg) & 1100 & 1100 & 1100 & 1100 & 1100 & 1100 & 1100 & 1100 \\
7 & Sodium lauryl sulfate (mg) & 150 & 150 & 150 & 150 & 150 & 150 & 150 & 150 \\
8 & Castor oil (mg) & 1900 & 1900 & 1900 & 1900 & 1900 & 1900 & 1900 & 1900 \\
9 & Methylparaben (mg) & 7.5 & 7.5 & 7.5 & 7.5 & 7.5 & 7.5 & 7.5 & 7.5 \\
10 & Distilled water (qs) (ml) & 100 & 100 & 100 & 100 & 100 & 100 & 100 & 100 \\
\hline
\end{tabular}

SA: Sodium alginate, HPMC: Hydroxypropyl methylcellulose

Table 2: Physical evaluations of gel formulations

\begin{tabular}{lllll}
\hline Formulations & Appearance & Feel on application & Gelling & pH \\
\hline F1 & Off white color & Smooth & +++ & 6.99 \\
F2 & Off white color & Smooth & +++ & 7.42 \\
F3 & Off white color & Smooth & ++ & 6.83 \\
F4 & Off white color & Smooth & ++ & 6.91 \\
F5 & Off white color & Smooth & +++ & 6.89 \\
F6 & Off white color & Smooth & ++ & 6.95 \\
F7 & Off white color & Smooth & +++ & 6.80 \\
F8 & Off white color & Smooth & +92 \\
\hline
\end{tabular}

Grades were allotted as + ++ + Excellent, ++ + Good ++ Fair, and +Poor 
Assay [10-14]

An amount of the formulated gel equivalent to $5 \mathrm{mg}$ tramadol was weighed and immersed in a $100 \mathrm{ml}$ volumetric flask containing $80 \mathrm{ml}$ of phosphate buffer (pH 7.4). The flask was stoppered and placed in a mechanical shaking water bath set at $37^{\circ} \mathrm{C}$ for $2 \mathrm{~h}$ to allow for complete dissolution of the drug and made up to volume with phosphate buffer. $20 \mathrm{ml}$ aliquot of this solution was withdrawn and placed in $100 \mathrm{ml}$ volumetric flask and the volume made up using distilled water. The ultraviolet (UV) absorbance of the solution was read at $272 \mathrm{~nm}$ using phosphate buffer $(\mathrm{pH} 7.4)$ as

Table 3: Viscosity and spreadability determination

\begin{tabular}{lll}
\hline Formulations & Viscosity (cps) & Spreadability (g) \\
\hline F2 & 2750 & 124.699 \\
F4 & 2420 & 120.187 \\
F6 & 2690 & 122.670 \\
F8 & 2540 & 121.142 \\
\hline
\end{tabular}

the blank. The tramadol content, in $\mu \mathrm{g} / \mathrm{ml}$, was determined from the absorbance value obtained and read against a standard calibration curve. This content was then calculated as a percentage of the expected concentration of tramadol. The results are mentioned in Table 4.

\section{Zeta potential}

Zeta potential was measured using Zetasizer Nano ZS (Malvern Instruments, Worcestershire, UK). The measurement was performed at $25^{\circ} \mathrm{C}$. The results are mentioned in Table 4 and Fig. 14 .

In vitro drug diffusion study [10-14]

Arrangement of assembly

- The in vitro release of tramadol gel from the prepared formulation through using double end open cylinder and is ready to diffuse from the cellophane membrane.

- The release medium used was phosphate buffer pH 7.4. Cellulose acetate paper was soaked for $2 \mathrm{~h}$ in phosphate buffer.

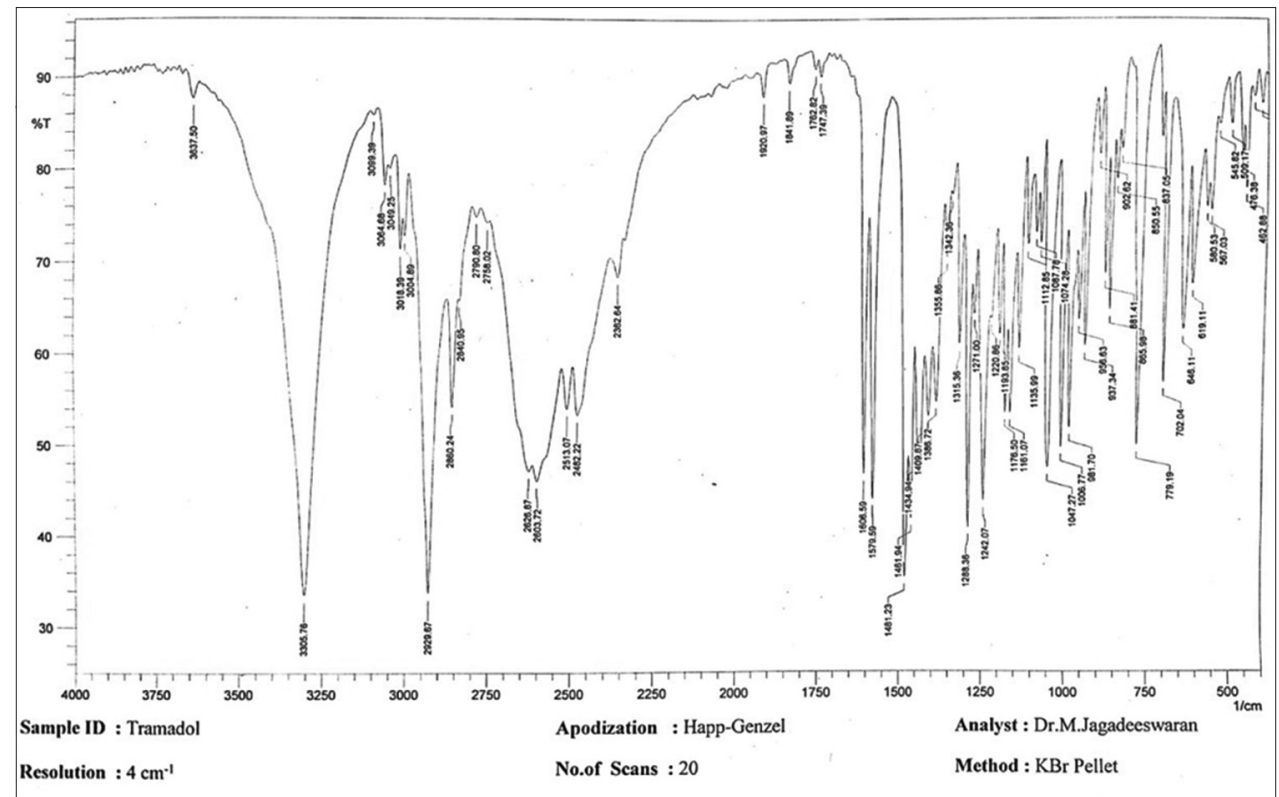

Fig. 3: Infrared spectrum of tramadol

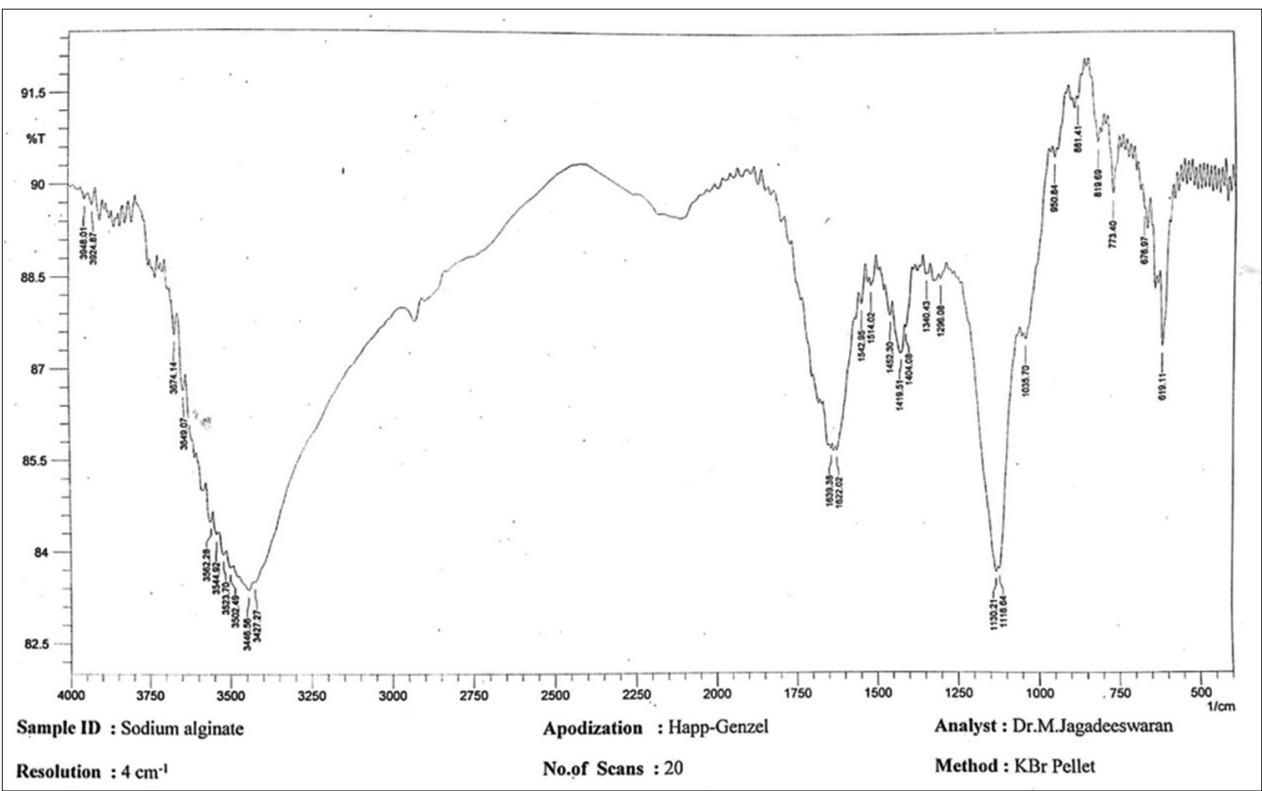

Fig. 4: Infrared spectrum of sodium alginate 


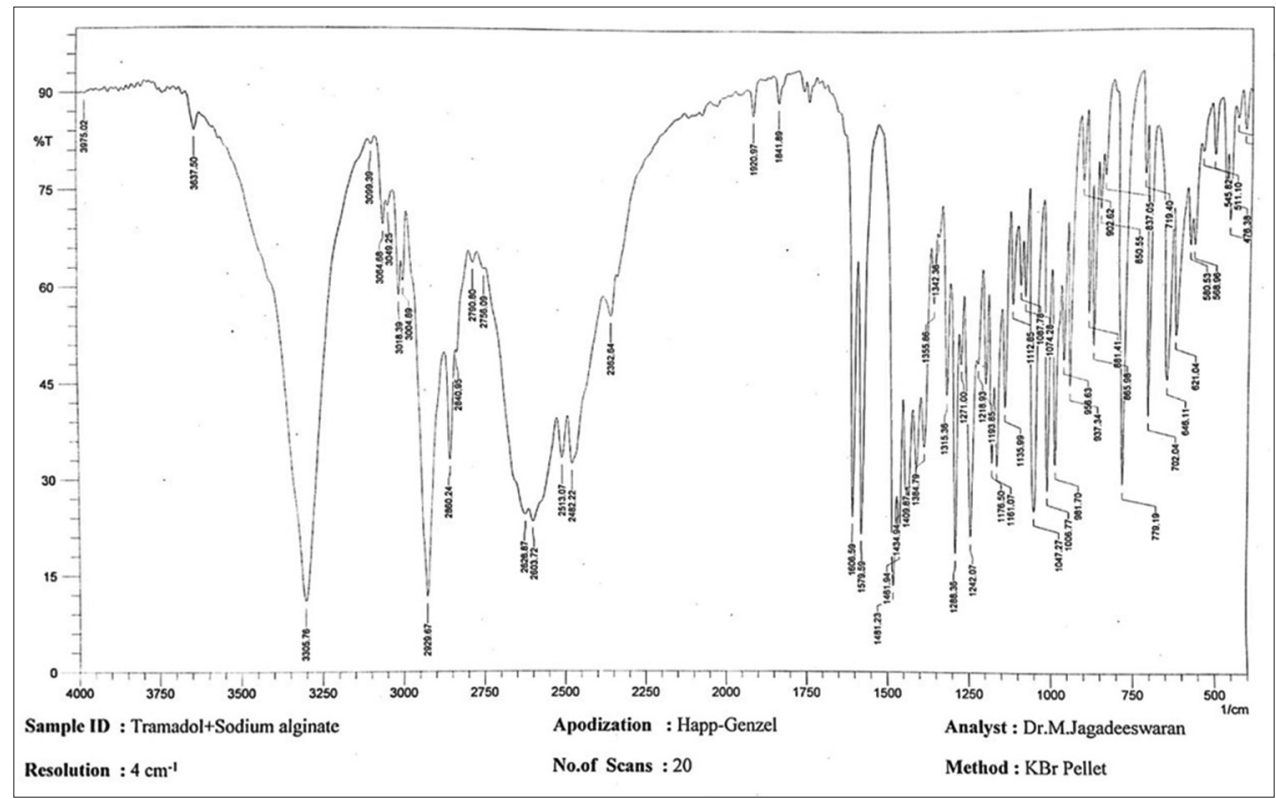

Fig. 5: Infrared spectrum of tramadol + sodium alginate

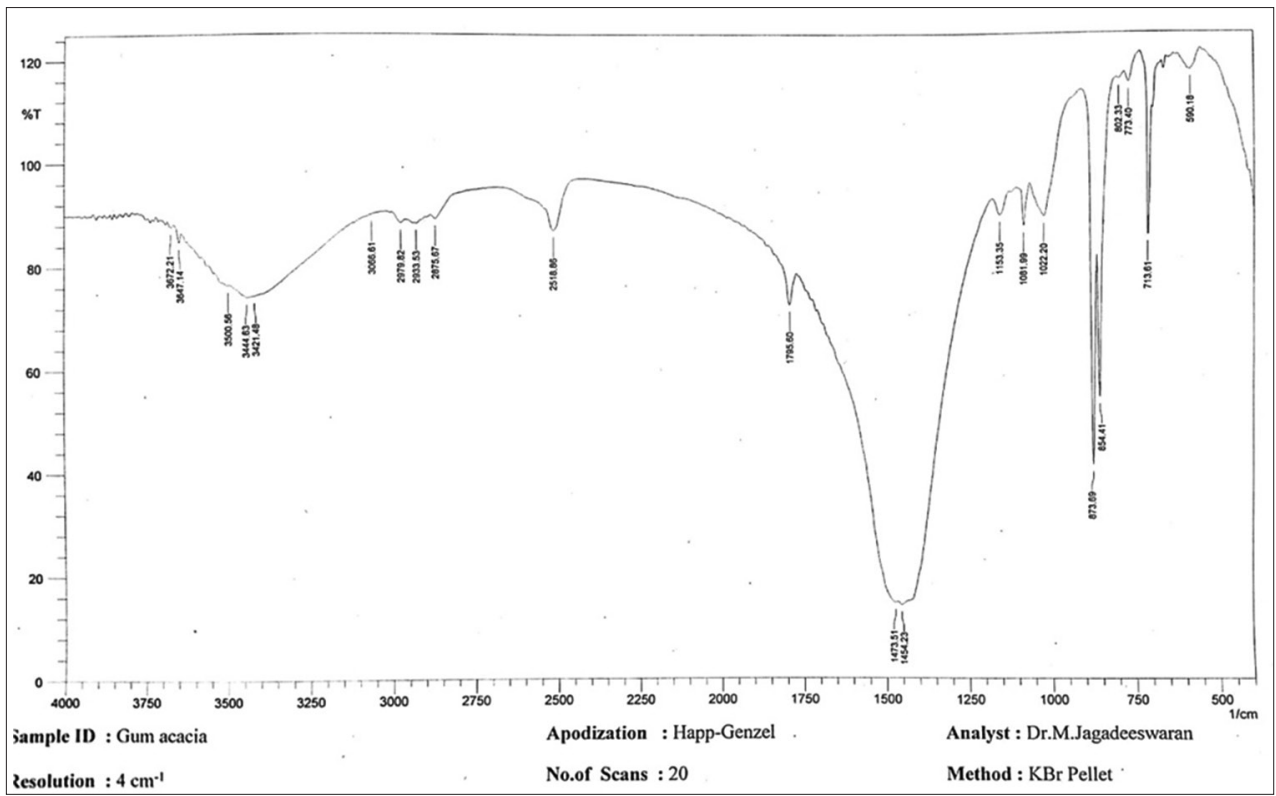

Fig. 6: Infrared spectrum of gum acacia

Table 4: Physicochemical evaluation of optimized gel formulation (F2)

\begin{tabular}{lll}
\hline S. No. & Evaluation parameters & Results \\
\hline 1 & Extrudability & $268.464 \mathrm{~g}$ \\
2 & Assay & $99.7 \%$ \\
3 & Zeta potential & $-26.1 \mathrm{Mv}$ \\
4 & Size distribution & $262.8($ d.nm) \\
\hline
\end{tabular}

- $2.5 \mathrm{~g}$ of the formulated gel (equivalent to $200 \mathrm{mg}$ tramadol) were weighed onto separate open end glass tube.

- The glass tube was then suspended in $250 \mathrm{ml}$ phosphate buffer $\mathrm{pH} 7.4$ solution maintained at $37 \pm 0.5^{\circ} \mathrm{C}$. The paddles were rotated at $75 \mathrm{rpm}$ and aliquots of $1 \mathrm{ml}$ withdrawn at 10,20,30,40, and 50 min and 1 , 2 , and $4 \mathrm{~h}$.

- Aliquots were replaced by equal volumes of the phosphate buffer solution. The absorbance of the aliquots was measured at $272 \mathrm{~nm}$.
Table 5: In vitro diffusion study of tramadol gel

\begin{tabular}{lllll}
\hline Time & F2 & F4 & F6 & F8 \\
\hline $10 \mathrm{~min}$ & 16.74 & 11.24 & 12.36 & 9.29 \\
$20 \mathrm{~min}$ & 25.26 & 20.82 & 23.12 & 19.43 \\
$30 \mathrm{~min}$ & 36.28 & 28.12 & 37.28 & 31.38 \\
$40 \mathrm{~min}$ & 47.86 & 38.48 & 41.22 & 43.92 \\
$50 \mathrm{~min}$ & 53.18 & 49.16 & 63.12 & 52.84 \\
$1 \mathrm{~h}$ & 64.26 & 63.28 & 75.64 & 65.46 \\
$2 \mathrm{~h}$ & 78.97 & 74.81 & 81.27 & 73.89 \\
$4 \mathrm{~h}$ & 89.17 & 79.72 & 84.13 & 80.74 \\
\hline
\end{tabular}

- The cumulative percentage drug release was calculated based on the concentrations obtained for the various gels overtime as a function of the loading doses (equivalent weight of tramadol in $1 \mathrm{~g}$ samples of the gel).

The results are mentioned in Table 5 


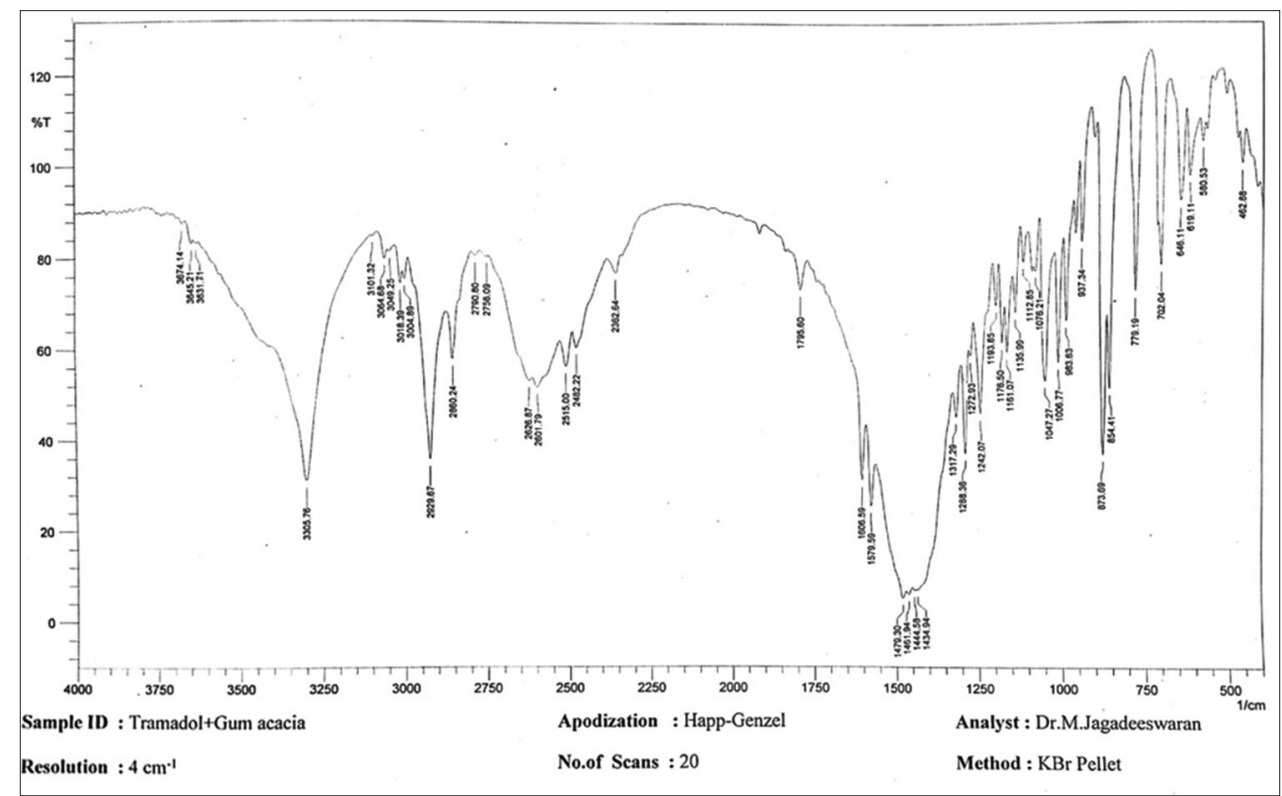

Fig. 7: Infrared spectrum of tramadol + gum acacia

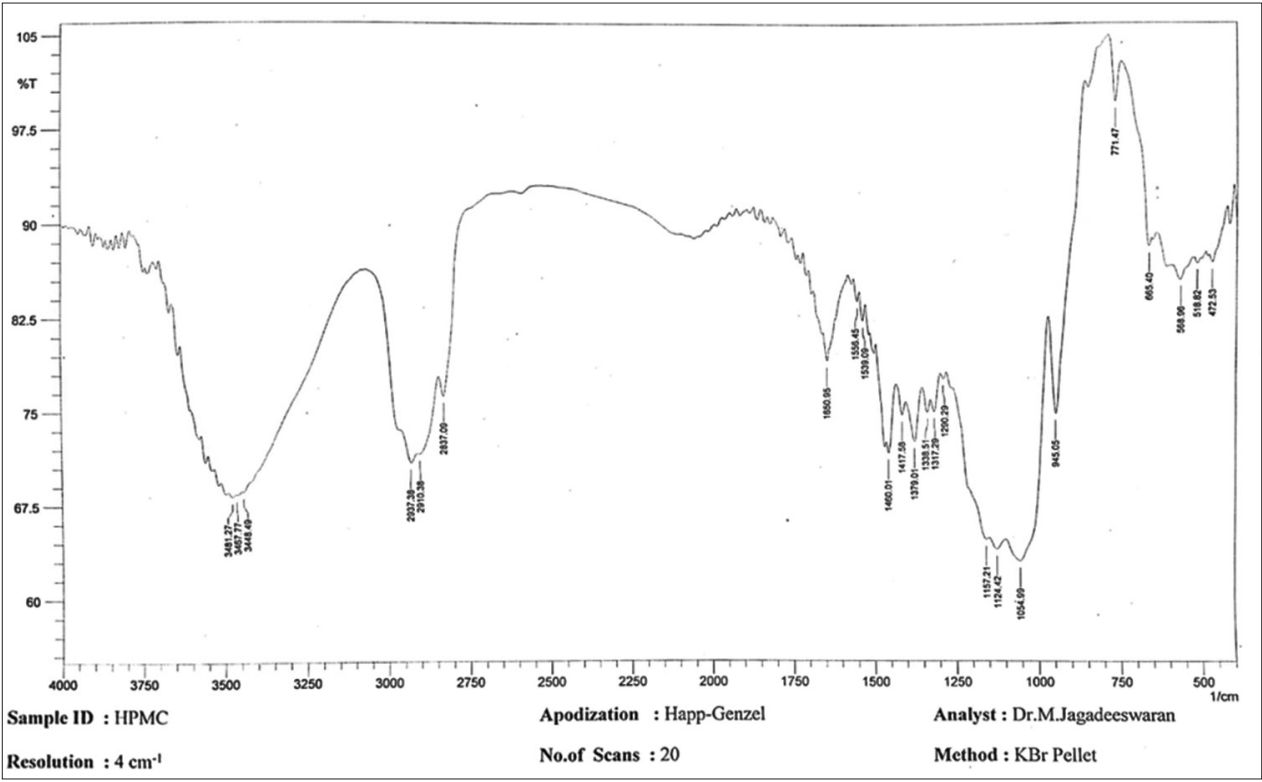

Fig. 8: Infrared spectrum of hydroxypropyl methylcellulose

Table 6: Stability parameter of selected formulation F2

\begin{tabular}{lll}
\hline Parameters & Initial & $\begin{array}{l}\text { After } \mathbf{1} \text { month } \\
\mathbf{4 0} / 7 \mathbf{7}\left({ }^{\circ} \mathbf{C} / \mathbf{R H}\right)\end{array}$ \\
\hline Appearance & $\begin{array}{l}\text { Off white } \\
\text { color } \\
\text { Smooth }\end{array}$ & Off white color \\
Feel on & & Smooth \\
application & 7.42 & 7.29 \\
pH & $2750 \mathrm{cps}$ & $2712 \mathrm{cps}$ \\
Viscosity & $124.699 \mathrm{~g}$ & $123.579 \mathrm{~g}$ \\
Spreadability & $268.464 \mathrm{~g}$ & $270.347 \mathrm{~g}$ \\
Extrudability & & \\
\hline
\end{tabular}

Stability studies [15-17]

Stability testing of the optimized formulation was performed to predict the quality of drug substance or drug product variation with time under the influence of changing environmental factors such as temperature,
Table 7: Standard calibration curve of tramadol

\begin{tabular}{ll}
\hline Concentration $(\mu \mathrm{g} / \mathrm{ml})$ & Absorbance \\
\hline 1 & 0.0371 \\
2 & 0.0624 \\
3 & 0.0831 \\
4 & 0.1252 \\
5 & 0.1511 \\
6 & 0.1742 \\
7 & 0.1935 \\
8 & 0.2201 \\
9 & 0.2414 \\
\hline
\end{tabular}

humidity and light, enabling recommended storage condition, retest periods, and shelf lives. To avoid this undesirable delay, the principles of accelerated stability studies are adopted. The results are mentioned in Table 6. 


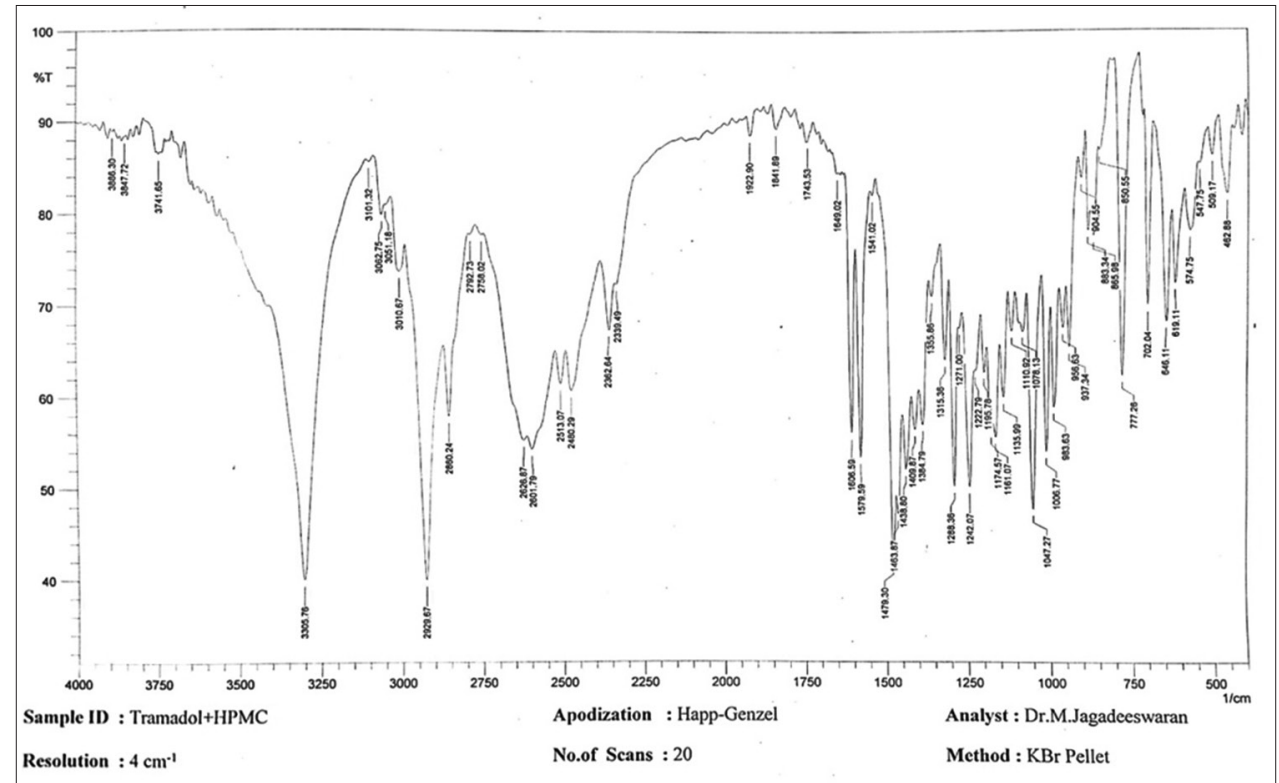

Fig. 9: Infrared spectrum of tramadol + hydroxypropyl methylcellulose

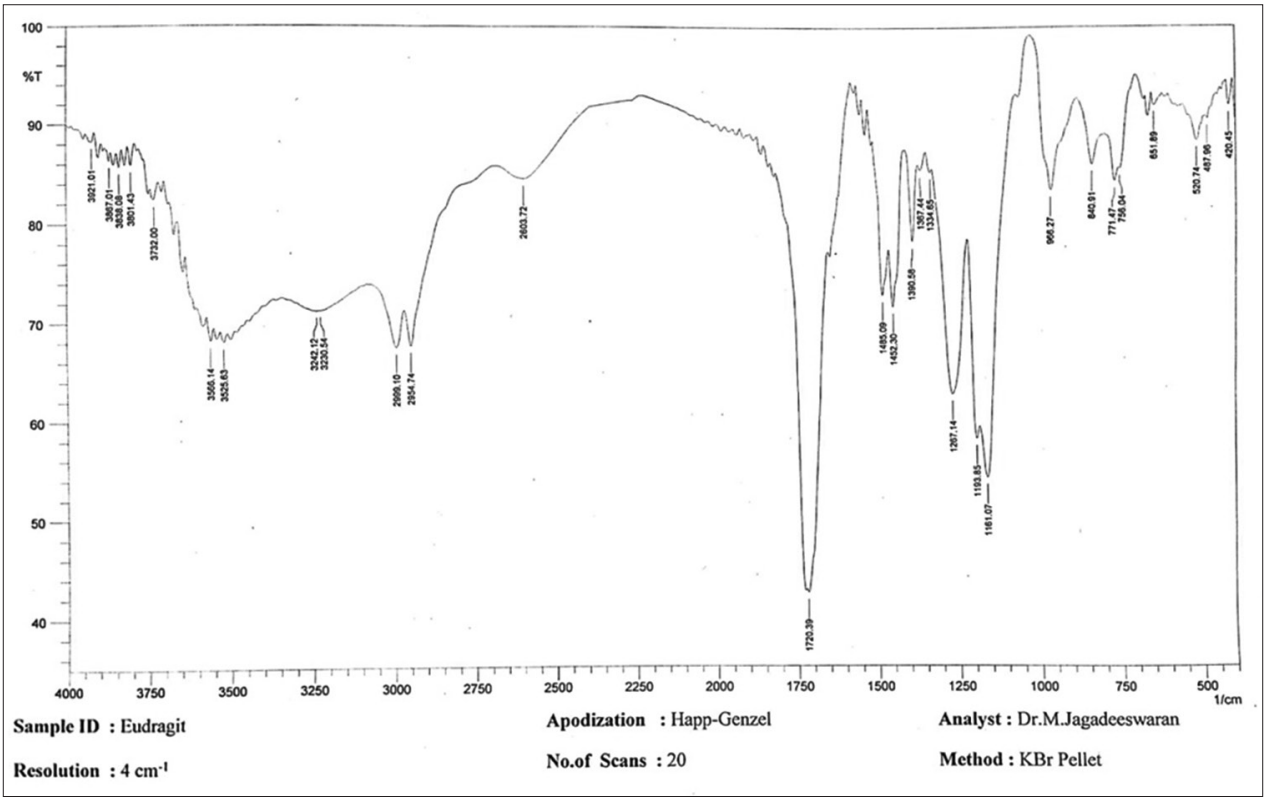

Fig. 10: Infrared spectrum of Eudragit

\section{RESULTS AND DISCUSSION}

The present study was carried out to develop gel tramadol to enhance absorption and bioavailability of the drug.

\section{Physicochemical properties}

Tramadol is a white crystalline powder with bitter taste, sparingly soluble in water $\left(1151 \mathrm{mg} / \mathrm{L}\right.$ at $\left.25^{\circ} \mathrm{C}\right)$ and freely soluble in alcohol and acid. Tramadol exhibits crystal polymorphism. Tramadol melting point was determined to be $180-181^{\circ} \mathrm{C}$ which was in compliance with the official value.

\section{UV spectroscopic study}

Tramadol in $0.1 \mathrm{~N}$ phosphate buffer solutions showed maximum absorbance $\left(\lambda_{\max }\right)$ of $272 \mathrm{~nm}$ and calibration curve exhibiting good linearity that obeys Beer-Lambert's law. The Beer-Lambert's concentration range was studied with a concentration range of $1-10 \mu \mathrm{g} / \mathrm{ml}$ at $272 \mathrm{~nm}$ showed coefficient of correlation value of 0.994 .
The slope and intercept values were 0.026 and 0.009 , respectively. The data are shown in Table 7 and Figs. 1 and 2.

\section{Drug and excipient interaction studies}

Drug-excipient interaction of tramadol and the polymers (SA, Acacia, Eudragit, and HPMC) studied in drug-excipient physical mixture showed no significant changes in the peak (at 163.88, 163.01, and $163.33^{\circ} \mathrm{C}$, respectively) of the drug in these mixtures, which refers that there was no interaction. The results are mentioned in Figs. 3-12.

The nitroglycerin (NTG)-magnesium stearate mixture was subjected to infrared (IR) studies and its spectrum was compared with the IR spectra of NTG. Characteristic bands of NTG were observed at 1647 $\mathrm{cm}^{-1}(-\mathrm{C}=0), 1713 \mathrm{~cm}^{-1}$ (-COOH), 2862-3096 cm ${ }^{-1}$ (-CH2-cycloalkane), and $3296 \mathrm{~cm}^{-1}$ (-NH stretching). However, the IR spectrum of the NTGmagnesium stearate mixture showed the respective characteristic bands of NTG at 1647, 1712, 2850-2953 (-CH2-cycloalkane), and 3300 


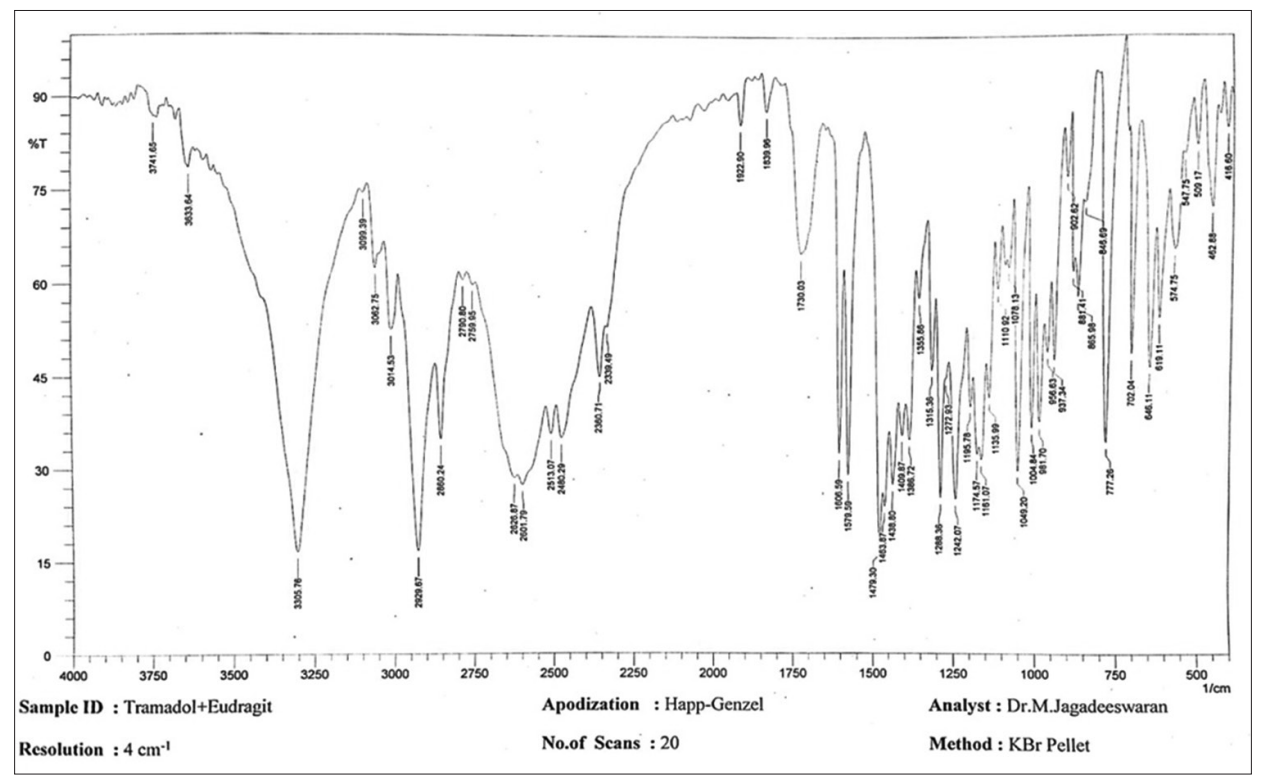

Fig. 11: Infrared spectrum of tramadol + Eudragit

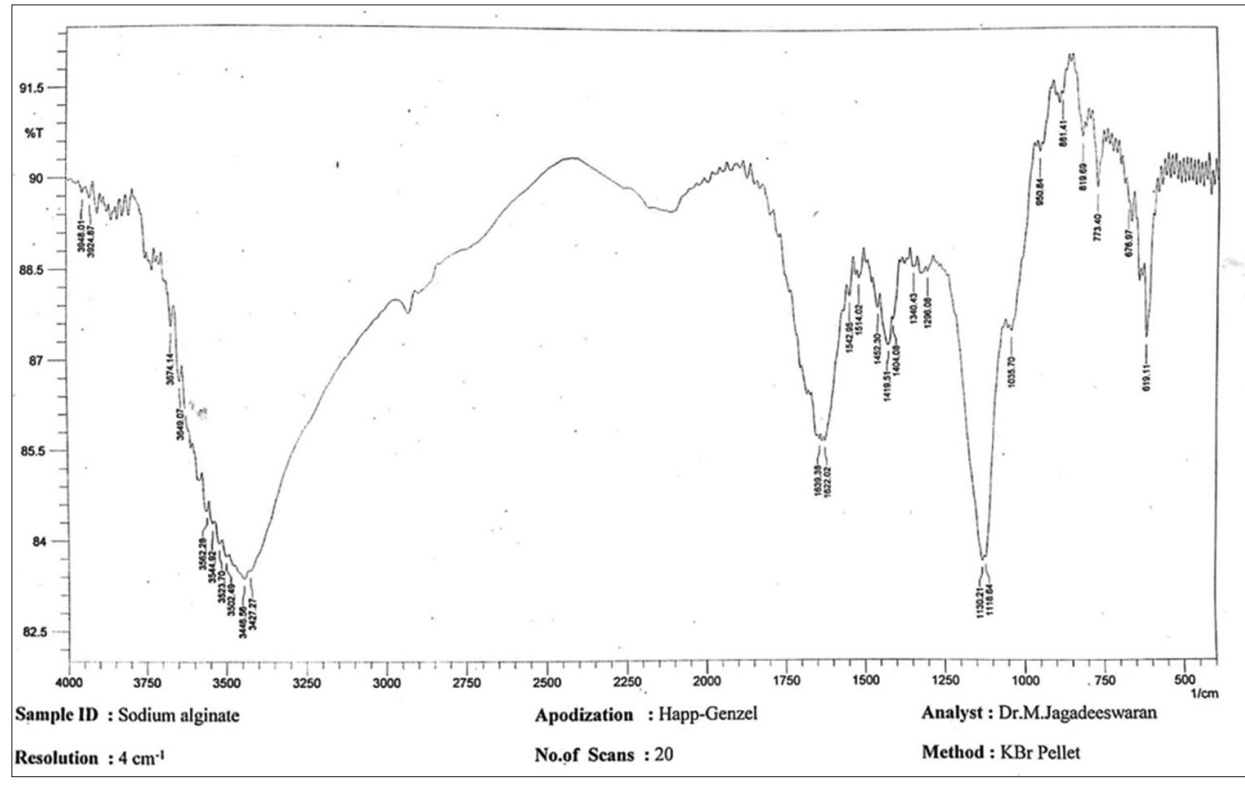

Fig. 12: Infrared spectrum of optimized formulation of F2

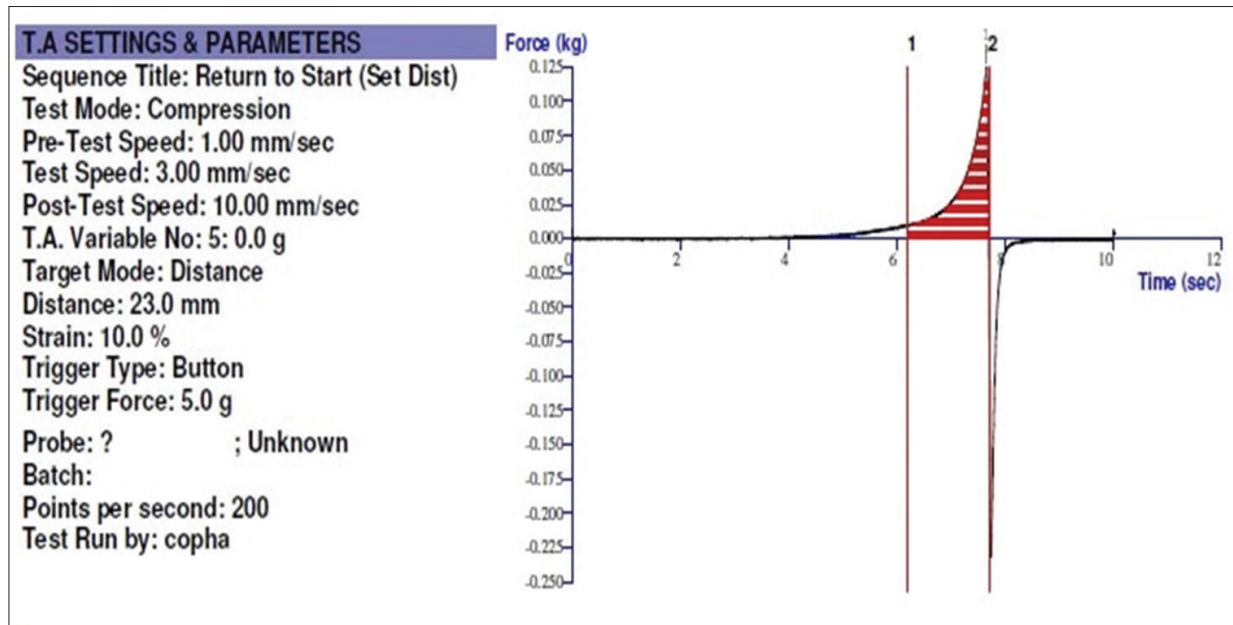

Fig. 13: Graph of spreadability 


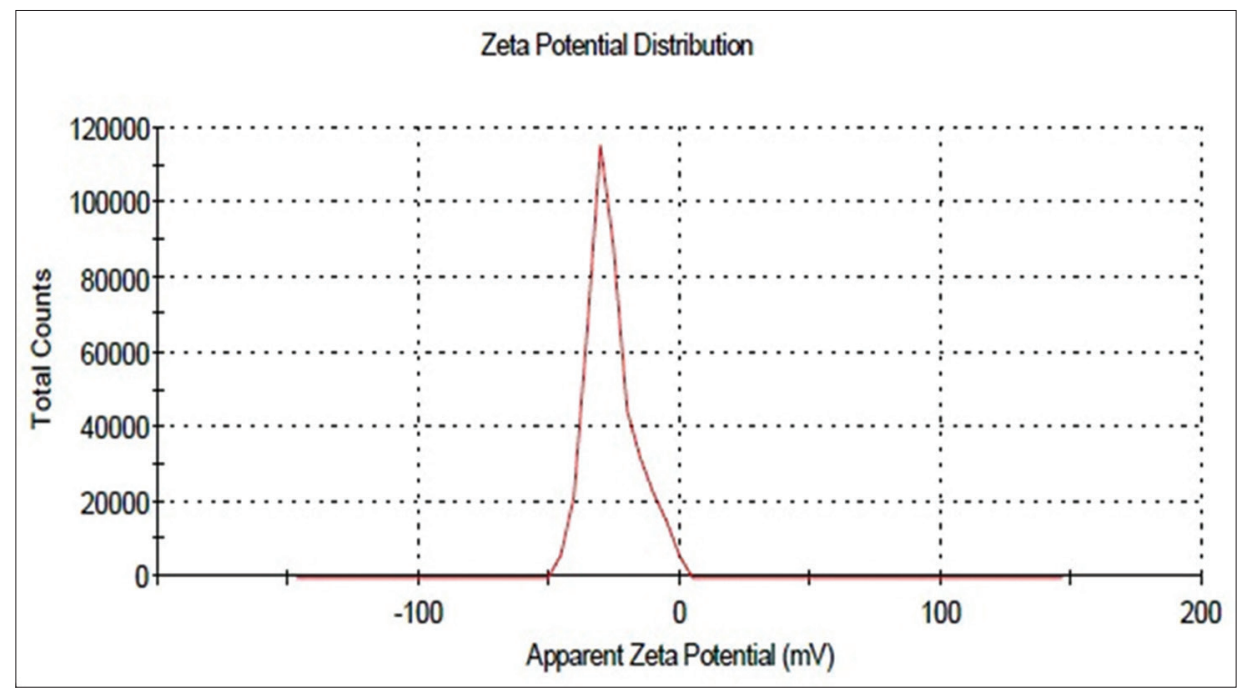

Fig. 14: Graph of zeta potential

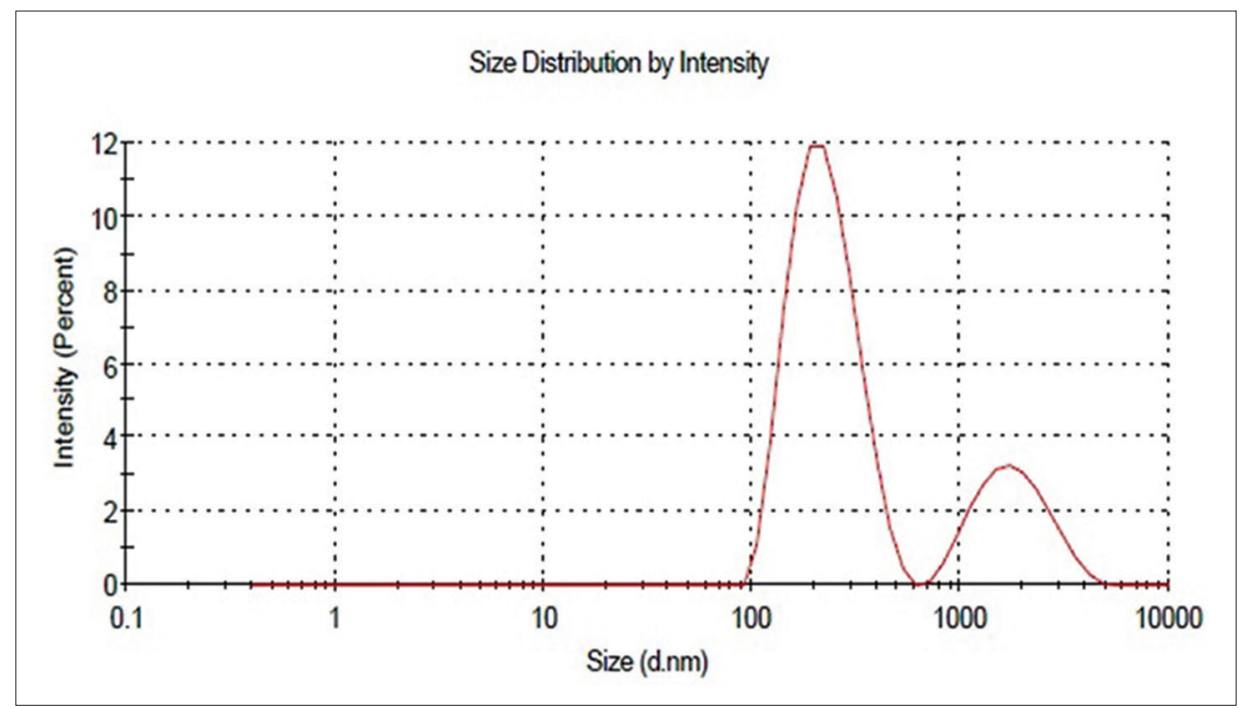

Fig. 15: Graph of size distribution

$\mathrm{cm}^{-1}$. The results confirmed that there was no chemical interaction between NTG and magnesium stearate.

\section{Evaluation of microemulsion gel formulations F1-F8}

Different methods were selected for the preparation of gel. These depend on the nature of polymer used (Discussed in methodology). Different concentrations of polymers were tried for the formulation of tramadol gel. The concentration of SA, Acacia, HPMC, and Eudragit was taken $1 \mathrm{~g}$ and $2 \mathrm{~g}$.

\section{Physical evaluation of gel formulations}

Evaluations such as physical appearance, texture of the gel, uniformity of the gel, and pH values studied results are mentioned in Table 2 and Fig. 15.

\section{Physicochemical evaluation}

Evaluations of the physicochemical properties for the selected formulation (F2, F4, F6, and F8) and optimized formulation (F2) are given in Tables 3 and 4.

Cumulative percentage drug release of microemulsion gel formulations

The cumulative percentage drug release from the selected formulations (F2, F4, F6, and F8) was studied exhibited the results as given in Table 5.

\section{Stability study}

Stability study was carried out for the optimized formulation according to ICH guidelines at $40^{\circ} \mathrm{C} / 75 \% \mathrm{RH}$ for 1 month. The results showed that there was no significant change in physical and chemical parameter of the gel; hence, the formulation (F2) was found to be stable (Table 6)

\section{CONCLUSION}

The present study was aimed to formulate and evaluate the microemulsion gel formulations of tramadol using various polymeric carriers. Based on the preformulation studies, further course of formulation and evaluation of optimized formulation of the drug were carried out with using different polymers and selected excipients.

The microemulsion gels were evaluated for physical characterizations ( $\mathrm{pH}$, appearance, spreadability, extrudability, and viscosity) and in vitro diffusion and optimized formulation suitable for better delivery of the drug was identified and studied further. The initial evaluation studies were indicative that the F2 formulation exhibited optimal results for the study parameters evaluated and showed to comply with the pharmacopoeial standard references. Further, the data from physical, physiochemical, and in vitro diffusion studies for the microemulsion gel formulation F2 directed in concluding that the F2 formulation has a better delivery capacity and can also be a promising dosage form 
for topical route of administration of the tramadol. Stability study was conducted of $\mathrm{F} 2$ stored at $40^{\circ} \mathrm{C} / 75 \% \mathrm{RH}$ for 1 month. Gels were evaluated for appearance, feel on application, $\mathrm{pH}$, viscosity, assay, and in vitro diffusion profile after 1 month. It concluded that formulation F2 was stable. From the above results, it concluded that tramadol gel formulation containing SA 3\% can be taken as an ideal formulation.

\section{AUTHORS' CONTRIBUTIONS}

M Prabakaran, C Pasupathi, LR Peely, and B. Pooja contributed to the design and implementation of the research, to the analysis of the results, and to the writing of the manuscript. Dr. V Muruganantham contributed to the final version of the manuscript and supervised the project.

\section{CONFLICTS OF INTEREST}

The authors declare that they have no conflicts of interest.

\section{REFERENCES}

1. Lawrence MJ, Rees GD. Microemulsion-based media as novel drug delivery systems. Adv Drug Deliv Rev 2000;45:89-121.

2. Cevc G, Vierl U. Nanotechnology and the transdermal route: A state of the art review and critical appraisal. J Control Release 2010;141:277-99.

3. Marti-Mestres G, Nielloud F. Emulsions in health care applications an overview. J Disperse Sci Tech 2002;23:419-39.

4. Ansel HC, Allen LV, Popovich NG. Pharmaceutical Dosage Forms and Drug Delivery Systems. $7^{\text {th }}$ ed. New York: Lippincott Williams and Wilkins; 1999.

5. Desai KG. Enhanced skin permeation of rofecoxib using topical microemulsion gel. Drug Dev Res 2004;63:33-40.

6. Barot BS, Parejiya PB, Patel HK, Mehta DM, Shelat PK. Microemulsion-based antifungal gel delivery to nail for the treatment of onychomycosis: Formulation, optimization, and efficacy studies. Drug Deliv Transl Res 2012;2:463-76.

7. Fanun M. Microemulsions as delivery systems. Curr Opin Colloid Interface Sci 2012;17:306-13.

8. Silva AE, Barratt G, Chéron M, Egito ES. Development of oil-in-water microemulsions for the oral delivery of amphotericin B. Int J Pharm 2013;454:641-8

9. Kandadi P, Syed MA, Goparaboina S, Veerabrahma K. Albumin coupled lipid nanoemulsions of diclofenac for targeted delivery to inflammation. Nanomedicine 2012;8:1162-71.

10. Saleem MA, Sanaullah S, Faizan S. Formulation and evaluation of gatifloxacin topical gels. Ind Pharm 2006;2:88-92.

11. Aulton ME. Pharmaceutics the Science of Dosage Form Design. $2^{\text {nd }}$ ed. Vol. 41. New York: Charchil Livingstone; 1988. p. 355-6.

12. Lieberman HA, Rieger MM, Banker GS. Schoenwald and Flanagan in Pharmaceutical Dosage Forms Vol-II Dispersed System. New York: Marcel Dekker; 1989. p. 145-152.

13. Baird R. British Pharmacopoeia. Vol. 2. London: HMSO; 1993. p. A184-90.

14. USP-NF 18 United State Pharmacopoeias. The National Formulary. Bethesda, Maryland: Mack Publishing Co; 1985. p. 1681-6.

15. Ahlneck C, Zografi G. The molecular basis of moisture effects on the physical and chemical stability of drugs in the solid state. Int J Pharm 1990;62:87-5.

16. ICH Guideline Published by Europian Medicines Agency CAMP/ ICH/2736/99 August; 2003.

17. Available from: http://www.ichguidelines.com. \{Last accessed on 2018 Feb]. 